\title{
The effect of chlorpromazine and imipramine on the aversive threshold of rats
}

\author{
VINCENT P. HOUSER and DALE A. VAN HART* \\ Psychotropic Drug Laboratory, VA Hospital, Perry Point, Maryland 21902
}

\begin{abstract}
An attempt was made to assay the analgesic potency of chlorpromazine $(.25,2.0,4.0,8.0 \mathrm{mg} / \mathrm{kg}) \mathrm{and}$ imipramine $(2.5,5.0,10.0,20.0 \mathrm{mg} / \mathrm{kg})$ in the rat, using the spatial preference technique. Chlorpromazine was able to raise the aversive threshold in a dose-dependent manner in doses at or above $2.0 \mathrm{mg} / \mathrm{kg}$. These same dosages, however, also significantly reduce the number of motor responses made during threshold testing. These results were interpreted to suggest that chlorpromazine produces analgesia and/or inhibits the execution of the escape response. Imipramine, on the other hand, significantly raised the aversive threshold without reducing motor activity. These results were interpreted to suggest that imipramine produced an analgesic effect.
\end{abstract}

The recent literature has reported that both chlorpromazine and imipramine can affect behavior under the control of schedules of reinforcement that employ electric shock. For example, chlorpromazine has been reported to impair active shuttlebox avoidance in rats (Posluns, 1970), passive avoidance in mice (Johnson, 1971), active avoidance in rats subjected to a multiple schedule (Weissman, 1959), and Sidman avoidance behavior in dogs.(Waller \& Waller, 1970) and in rats and monkeys (Hanson, 1961). Similarly, imipramine has been reported to impair the performance of Sidman avoidance in rats and monkeys (Hanson, 1961; Kornetsky, 1965). Although various explanations have been offered to account for these results, it is possible that these two agents may affect behaviors under the control of aversive schedules of reinforcement by means of drug-induced analgesia. Both chlorpromazine and imipramine are known to possess potent local anesthetic activity (Goodman \& Gilman, 1965; Ritchie \& Greengard, 1961). Furthermore, chlorpromazine demonstrates analgesic activity in the mouse tail-flick test (Weller \& Sulman, 1970) and significantly elevates the aversive threshold in monkeys performing under a titration schedule (Weiss \& Laties, 1970; Weitzman \& Ross, 1962).

The present paper is an attempt to determine whether these two agents possess significant analgesic properties in the rat. To accomplish this end, animals were subjected to the spatial preference technique, a method developed in our laboratories to assay the analgesic qualities of various drugs. This technique appears to have several advantages over previous pharmacological procedures used to detect analgesia. Unlike such animal models as the tail-flick or hot-plate procedures, the spatial preference technique can detect anagesia in all

*The authors wish to express their appreciation to Richard L. Seiser for his assistance in gathering the data and to Luther $R$. Gilliam, Medical mlustration Service, VA Hospital, Perry Point, Maryland, for performing the photographic work. three major classes of analgesic agents known to be active in man (Houser \& Paré, 1973a, b). Previous reports have indicated that this technique is sensitive to a number of weak analgesics [e.g., sodium salicylate, indomethacin (Houser \& Paré, 1973b)], narcotic antagonist analgesics [e.g., pentazocine, cyclazocine (Houser \& Paré, 1973a)], as well as the classic narcotic analgesics [e.g., morphine (Houser \& Paré, 1972), codeine, and meperidine hydrochloride (Houser \& Paré, 1973a)]. Furthermore, this technique appears to be selective in that it does not react to sedative doses of sodium pentobarbital (Houser \& Paré, 1973a) or to high doses of scopolamine hydrobromide (Houser \& Van Hart, 1973). Therefore, the spatial preference technique may be superior to such analgesic assays as writhing induced by chemicals, which lack this selectivity and therefore react to a host of agents which are clinically nonanalgesic (Turner, 1965).

The above evidence suggests that the spatial preference technique may be a more sensitive and selective measure of drug-induced analgesia than previous pharmacological assays. Thus, by utilizing this technique, the present report may supply more definitive evidence as to whether chlorpromazine and/or imipramine possess analgesic activity.

\section{METHOD}

\section{Subjects}

Twelve male Sprague-Dawley derived rats obtained from ARS/Sprague-Dawley, Madison, Wisconsin, were used in the present study. They weighed $213-250 \mathrm{~g}$ at the beginning of the experiment.

\section{Apparatus}

The test chamber and apparatus have been described in detail elsewhere (Houser \& Paré, 1972). Briefly, the chamber consisted of a rectangular Plexiglas shuttlebox which was pivoted in the middle, allowing the box to tilt from side to side as the animal crossed from one end to the other. This tilting movement 




Fig. 1. Mean aversive thresholds with corresponding standard error of the means for those animals subjected to chlorpromazine. Each bar represents the mean of three consecutive daily sessions under saline (S) or various dosages of chlorpromazine. All doses are given in $\mathrm{mg} / \mathbf{k g}$.

activated a light action Acro lever switch, located at one end of the cage, which controlled the presentation of shock. The stainless steel rods which formed the floor of the cage could be electrified by various intensities of shock. The shock stimulus was provided by a dc generator which produced a $60-\mathrm{Hz}$ square-wave output (Reus, Houser, \& Paré, 1971). Standard electromechanical scheduling and recording equipment was used to automatically present the various shock intensities and to record the amount of time in seconds spent on the shock side of the cage and number of crossing responses made during each intensity.

\section{Procedure}

Each animal was subjected to a 50 -min experimental session, the same time each day, 6 days a week. An experimental session consists of five $10-\mathrm{min}$ periods in which five separate current intensities (i.e., $30,60,90,120,150$ microA) were presented in an ascending order. The shock was presented continuously on one side of the cage for $5 \mathrm{~min}$ and then switched to the other side for the remaining $5 \mathrm{~min}$ of each current intensity. The animal could escape the shock side of the cage by merely crossing to the opposite or nonshock portion of the tilt cage. The shock was automatically switched from one side to the other every $5 \mathrm{~min}$ to insure that each animal sampled all shock intensities even if it failed to make a crossing response during the 10-min period that each intensity was presented.

The dependent measure consisted of the amount of time in seconds spent on the shock side of the cage for each shock intensity. The aversive threshold was calculated daily for each animal by determining the intensity of shock which an animal avoided $75 \%$ of the time. At subthreshold intensities, the animal, by chance, would spend $50 \%$ of the time on the shock side of the cage. Since time spent on the shock side diminished as the shock intensity increased, the $75 \%$ threshold criteria required a simple interpolation process. If animals spent more than $25 \%$ of the available time on the shock side at the highest intensity (i.e., 150 microA), as was the case under some drug conditions, an aversive threshold could not be interpolated since no higher levels were presented. In these cases, a threshold value of 150 microA was arbitrarily assigned.

After 10 sessions, all animals demonstrated stable threshold values. Animals were then randomly assigned to two separate six-animal drug groups. Each drug was given in several separate doses in consecutive weekly series. Saline was administered for the first 3 days of each weekly series, followed by 3 days of a particular drug dosage. Animals were not tested on the seventh day of these weekly series.
The two drugs administered in the present study consisted of chlorpromazine hydrochloride $(.25,2.0,4.0,8.0 \mathrm{mg} / \mathrm{kg})$ and imipramine hydrochloride $(2.5,5.0,10.0,20.0 \mathrm{mg} / \mathrm{kg})$. Both drugs were delivered in $.9 \%$ saline and administered intraperitoneally in a volume of $1.0 \mathrm{mg} / \mathrm{kg}$. Since imipramine hydrochloride is not highly soluble in saline, several drops of tween 80 were added to form a uniform suspension. Both drugs were administered $1 / 2 \mathrm{~h}$ before threshold testing.

\section{RESULTS}

Figure 1 presents the mean aversive thresholds with corresponding standard error of the means for those animals subjected to the various dosages of chlorpromazine $(.25,2.0,4.0,8.0 \mathrm{mg} / \mathrm{kg})$. The data contained in Fig. 1 indicate that chlorpromazine was able to increase the aversive threshold in a dose-related manner. A two-factor within analysis of variance (Meyers, 1966) indicated that all doses at or above $2.0 \mathrm{mg} / \mathrm{kg}$ elevated the aversive threshold to levels that were statistically significant $(p<.05)$. All statistical tests were performed by comparing each dosage series with the saline series which immediately preceded it.

Figure 2 presents the mean number of crossing responses made during saline and the various chlorpromazine dosage sessions. Each bar represents the mean number of crossing responses made during three consecutive saline or drug dosage sessions. The data in Fig. 2 indicate that chlorpromazine reduced the total number of crossing responses made during all drug dosage sessions. An analysis of variance indicated that all dosages significantly reduced the total number of crossings made during the drug sessions $(p<.025)$.

Finally, Fig. 3 presents the mean aversive thresholds and standard error of the means for those animals subjected to the various dosages $(2.5,5.0,10.0$, $20.0 \mathrm{mg} / \mathrm{kg}$ ) of imipramine. The data in Fig. 3 indicate that imipramine in doses at or above $5.0 \mathrm{mg} / \mathrm{kg}$ was able to increase the aversive threshold in rats $(p<.005)$. These increments were not dose related, however, since 
Fig. 2. Mean number of crossing responses with corresponding standard error of the means for the various saline and chlorpromazine dosage sessions. All dosages are given in $\mathrm{mg} / \mathrm{kg}$.



$-p<.025$

$\bullet p<.01$ the higher dosages did not appear to produce greater increments in this measure than the lower dosages. The three highest dosages $(5.0,10.0,20.0 \mathrm{mg} / \mathrm{kg})$ augmented the aversive threshold above the preceding saline value by equivalent amounts. The fact that the $20.0-\mathrm{mg} / \mathrm{kg}$ threshold appears lower than the previous dosages merely reflects a reduction in the baseline saline value preceding this dose of the drug. An analysis of the crossing data revealed that imipramine in all dosages produced no significant changes in motor activity.

\section{DISCUSSION}

Chlorpromazine was able to raise the aversive threshold in a dose-related manner. Significant evaluations were noted in doses at or above $2.0 \mathrm{mg} / \mathrm{kg}$. These data could be used to suggest that chlorpromazine produces analgesia by acting on the central nervous system to reduce the motivational properties of electric shock. Although chlorpromazine is a potent local anesthetic, it is unlikely that the drug given intraperitoneally could cause significant peripheral nerve blockade to account for the present results. It is more likely that chlorpromazine acted on the central nervous system to produce this apparent analgesic effect. Previous reports (Sollmann, 1957) have noted that pain may be relieved in one of two distinct ways: (1) by disrupting the sensation of pain by blocking the sensory nerves, and/or (2) by reducing the conscious appreciation of pain by dulling the emotional state which accompanies pain. In the case of chlorpromazine, a known tranquilizing agent, it would appear more likely that analgesia would be produced by reducing the emotional rather than the sensory component of pain.

Other explanations, however, which do not assume that analgesia is the cause of the increase in the aversive threshold, could be used to account for the present results. For example, it is possible that the decrease in motor activity as indicated by the reduction in the number of crossing responses represented drug-induced sedation which could have increased the escape latencies, thus elevating the aversive threshold. In support of this explanation, Boyd and Miller (1954) have reported that chlorpromazine produces an avoidance decrement in a one-way shuttlebox even when shock intensity is increased, suggesting that this.effect is not the result of a sensory deficit. This author (Posluns, 1970) concluded that chlorpromazine produced the avoidance decrement
Fig. 3. Mean aversive thresholds with corresponding standard error of the means for those animals subjected to imipramine. Each bar represents the mean of three consecutive daily sessions under saline (S) or various dosages of imipramine. All doses are given in $\mathbf{m g} / \mathbf{k g}$.




by inducing a delay in the initiation of locomotion without affecting the efficacy of the avoidance response reinforcer. These data would support the conclusion that the increase in the aversive threshold noted in the present report could be a result of a reduction in motor activity (i.e., the number of responses emitted as well as a delay in the initiation of the response). Thus, the present data could be interpreted to suggest that chlorpromazine elevates the aversive threshold by a direct analgesic effect and/or by interfering with the execution of the motor response.

Imipramine, on the other hand, significantly elevated the aversive threshold without affecting the number of motor responses made by the animals. As was the case with chlorpromazine, it is unlikely that imipramine produced this analgesic effect by means of its local anesthetic properties. Since the drug was given intraperitoneally, it would probably not be available in sufficient quantity to fully block the activity of peripheral sensory nerves. It is more likely that imipramine produced its analgesic effects by acting on the central nervous system to reduce the emotional or motivational component of pain. Imipramine is classified primarily as an antidepressant which is used clinically to treat depressive states (Goodman \& Gilman, 1965). Since this drug is known to alter affective states in man, it is not unreasonable to suggest that it may have similar effects in rodents by reducing the emotional or motivational components of pain produced by electric shock. The above suggestion may be useful in framing explanations to account for the fact that imipramine has been reported to produce a loss of avoidance responding in rats (Kornetsky, 1965).

\section{REFERENCES}

Boyd, E. M., \& Miller, J. K. Inhibition of locomotor activity by chlorpromazine hydrochloride. Federation Proceedings, 1954 $13,338$.

Goodman, L. S., \& Gilman, A. The pharmacological basis of therapeutics. New York: Macmillan, 1965.
Hanson, H. M. The effects of amitriptyline, imipramine, chlorpromazine and nialamide on avoidance behavior. Federation Proceedings, 1961, 20, 396.

Houser, V. P., \& Parê, W. P. A method for determining the aversive threshold in the rat using repeated measures: Tests with morphine sulfate. Behavior Research Methods \& Instrumentation, 1972, 4, 135-137.

Houser, V. P., \& Pare, W. P. Measurement of analgesia using a spatial preference test in the rat. Physiology \& Behavior, 1973a, 10, 535-538.

Houser, V. P., \& Paré, W. P. Analgesic potency of sodium salicylate, indomethacin, and chlordiazepoxide as measured by the spatial preference technique in the rat. Psychopharmacologia, 1973b, 32, 121-131.

Houser, V. P., \& Van Hart, D. A. The effects of scopolamine and pilocarpine upon the aversive threshold of the rat Pharmacology, Biochemistry \& Behavior, 1973, 1, 427-431.

Johnson, F. N. Stimulus significance ana chlorpromazine-induced impairment of avoidance learning. Neuropharm acology, 1971, 10, 9-14.

Kornetsky, C. A comparison of the effects of desipramine and imipramine on two schedules of reinforcement. International Journal of Neuropharmacology, 1965, 4, 13-16.

Myers, J. Fundamentals of experimental design. Boston: Allyn \& Bacon, 1966.

Posluns, D. An analysis of chlorpromazine-induced suppression of the avoidance response. In $T$. Thompson, $R$. Pickens, and R. A. Meisch (Eds.), Readings in behavioral pharmacology. New York: Appleton-Century-Crofts, 1970. Pp. 349-361.

Reus, J., Houser, V. P., \& Paré, W. P. An electronic constant current shock generator for low current levels. Physiology \& Behavior, 1971, 7, 635-637.

Ritchie, J. M., \& Greengard, P. On the active structure of local anesthetics. Journal of Pharmacology \& Experimental Therapeutics, 1961, 133, 241-245.

Sollmann, T. A manual of pharmacology. Philadelphia: Saunders, 1957.

Turner, R. A. Screening methods in pharmacology. New York: Academic Press, 1965.

Waller, M. B., \& Waller, P. F. Effects of chlorpromazine on appetitive and aversive components of a multiple schedule. In T. Thompson, R. Pickens, and R. A. Meisch (Eds.), Readings in behavioral pharmacology. New York: Appleton-Century-Crofts, 1970. Pp. 341-348.

Weiss, B., \& Laties, V. The psychophysics of pain and analgesia in animals. In W. C. Stebbins (Ed.), Animal psychophysics. New York: Appleton-Century-Crofts, 1970. Pp. 185-210.

Weissman, A. Differential drug effects upon a three-ply multiple schedule of reinforcement. Journal of the Experimental Analysis of Behavior, 1959, 2, 271-287.

Weitzman, E. D., \& Ross, G. S. A behavioral method for the study of pain perception in the monkey. The effects of some pharm acological agents. Neurology, 1962, 12, 265-272.

Weller, C. P., \& Sulman, F. G. Drug action on tail shock-induced vocalization in mice and its relevance to analgesia. European Journal of Pharmacology, 1970, 9, 227-234.

(Received for publication February 12, 1974; revision received April 4, 1974.) 